\title{
FEATURES OF 5G TERMINALS WITH QOS PROVISIONING AND VERTICAL MULTI-HOMING AND MULTI-STREAMING
}

\author{
Tomislav Šuminoski, Toni Janevski \\ Faculty of Electrical Engineering and Information Technologies, \\ "Ss. Cyril and Methodius" University in Skopje, \\ Rugjer Bošković bb, P.O. box 574, 1001 Skopje, Republic of Macedonia \\ tomish@ feit.ukim.edu.mk
}

\begin{abstract}
A b s t r a c t: The major issue presented in this paper is a novel QoS and vertical multi-homing and multistreaming framework for the fifth generation $(5 \mathrm{G})$ of mobile terminals with radio network aggregation capability; using Lyapunov optimization in 5G mobile and wireless networks. The proposed 5G (mobile and fixed) terminal is leading to high performance utility networks with high QoS provisioning for any given multimedia service, higher bandwidth utilization, traffic load sharing, lower consumption of power and multi-radio interface capabilities. Our framework is user-centric, targeted to always-on connectivity with using radio network aggregation for achieving broadband connections, maximal network utilization, minimal battery life time, maximal throughput and performances improvement. Moreover, our proposed framework is using Lyapunov drift-plus-penalty theorem that provides a methodology for designing algorithm to maximize the average throughput and stabilize the queuing, leading to minimal queue delays. Also, we are showing the upper bound of the consumed power and the lower bound of the battery life time for the proposed $5 \mathrm{G}$ terminal. The performance of our $5 \mathrm{G}$ terminal framework is evaluated using simulations and analysis with multimedia traffic in heterogeneous mobile and wireless environment.
\end{abstract}

Key words: 5G terminal; aggregation; Lyapunov optimization; quality of service; vertical multi-homing

\section{КАРАКТЕРИСТИКИ НА 5G ТЕРМИНАЛИ СО ОБЕЗБЕДЕН КВАЛИТЕТ НА СЕРВИС QoS И ВЕРТИКАЛНИ MULTI-HOMING И MULTI-STREAMING}

А п с т р а к т: Главното нешто што е презентирано во овој труд е нова рамка-водилка со QoS и вертикални multi-homing и multi-streaming за петтата генерација (5G) мобилни терминали со можност за радиомрежна агрегација; користејќи Лјапунова оптимизација во 5G мобилните и безжични мрежи. Предложениот 5G (мобилен и фиксен) терминал постигнува: високи мрежни перформансни искористености со висока QoS обезбеденост за било кој мултимедиски сервис, висока искористеност на опсегот, балансирано сообраќајно оптоварување, ниска потрошувачка на моќност и можности за едновремено користење на повеќе радио интерфејси. Нашата рамка-водилка е кориснички центрирана, наменета за постојана поврзаност, користејќи радио-мрежна агрегација за постигнување на широкопојасни врски, максимална искористеност на достапните мрежи, максимално времетраење на батеријата, максимален битов проток и други перформансни подобрувања. Наедно, предложената рамка-водилка ја користи Лјапунов drift-plus-penalty теорема за да обезбеди методологија за дизајнирање алгоритам кој го максимизира просечниот проток и ги стабилизира редовите на чекање. Тоа води кон помали доцнења на редовите на чекање, како и помало севкупно доцнење во мрежата. Исто така ја докажуваме горната граница на искористената моќност и долната граница на времето на живот на батеријата за предложениот 5G терминал. Перформансите за нашиот 5G терминал се евалуирани со користење на симулации и анализи со употреба на мултимедиски сообраќај во хетерогена мобилна и безжична средина.

Клучни зборови: 5G терминали; агрегација; Лјапунова оптимизација; квалитет на сервис; вертикален multi-homing

\section{INTRODUCTION}

Today we are living at the period of transition from $4 \mathrm{G}$ toward $5 \mathrm{G}$, and moreover until the end of
2020 we should have the first $5 \mathrm{G}$ deployment. This paper provides $5 \mathrm{G}$ mobile and fixed technology framework that could lead to high performance utility networks with high QoS provisioning for 
any given multimedia service, using any existing and future RATs (Radio Access Technologies). Looking beyond network implementations and improvements, the $5 \mathrm{G}$ networks will require smarter devices capable to provide broadband multimedia services to mobile users, with ubiquitous mobility, enormous processing power of the mobile equipment, machine-to-machine communications, massive MIMO, better network utilization and load balancing, multi-homing features, advanced QoS support, as well as bigger memory space and longer battery life of mobile terminals (MTs), and enormous spectrum for advanced capabilities [18]. The exponential growth in the amount of traffic carried through mobile networks is followed by a novel research and development works towards the $5 \mathrm{G}$ era.

Moreover, in the future, each wireless and mobile network will be responsible for handling user-mobility, while the terminal will make the final choice among different wireless/mobile access network providers (different RATs) for a given service or traffic flow. In that context, QoS provisioning for wireless and mobile multimedia networks is becoming increasingly important objective, since it requires great thoughtfulness, scalability and thoroughfull analysis. Since radio bandwidth is one of the most precious resources in wireless and mobile systems, an efficient QoS framework is very important to guarantee the required QoS and to maximize radio resource utilization simultaneously in all present wireless and mobile networks. We have used the throughput parameter as a performance metric. Moreover, the user throughput also defines the generations of the mobile network. On the other hand, in a heterogeneous wireless network, with different multimedia traffic flows, each with different QoS requirements, achieving higher access probability of any given service is essential.

The key goal of this paper is to propose a novel radio network aggregation technique for future $5 \mathrm{G}$ mobile networks by maximization of radio access throughput, with high level of QoS support and advanced QoS routing algorithm. Moreover, without loss of generality, the proposed advanced QoS routing framework and mobile terminal design can be used in any mobile and wireless IP multimedia networks, including existing RATs as well as future ones. Therefore, in our proposal we have not tied to any of existing RATs. However, nowadays smartphones and other mobile devices use only one RAT at a given moment for a given flow. When there are different wireless and mobile networks on one side, and single mobile equipment on the other, then consequently the user of that mobile terminal should have possibility to use all available RATs in the range using his/her personal settings in the mobile terminal or this user can choose only subset of them.

Undoubtedly, in the future generation mobile networks, the $5 \mathrm{G}$ is moving towards the user-centric concept, which is the main reason why the user-centric approach is accepted as a basis for our work. The analysis and design methodology of our proposed system is based on the adaptive queuing Lyapunov optimization techniques [9], which are powerful techniques for optimizing time average queuing networks and giving joint stability and performance optimization. The solutions and applications are including maximization of the aggregated throughput subject to average power constraints on the terminal interfaces (implies longer battery life), minimizing average queue backlogs, subject to minimal queue network delay and in the same time achieving network stability.

The remainder of this paper is organized as follows. Section 2 gives an overview of the most relevant research works in this field. Section 3 presents the system design of the $5 \mathrm{G}$ terminal with advanced QoS module within and Lyapunov optimization technique. Furthermore, in Section 4 are given the bounds of the consumed power and battery life time for the proposed $5 \mathrm{G}$ terminals with AQUAplus algorithm within. In Section 5 we provide simulation results. Finally, the last Section 6 concludes this paper.

\section{RELATED WORKS}

The interest for high level of QoS provisioning in any telecommunication network is growing together with the tremendous development of multimedia services in mobile and wireless networks, where it is possible to increase or decrease the bandwidth of individual ongoing flows. In our 5G terminals are implemented Lyapunov drift-pluspenalty techniques, which for the first time were applied to wireless networks in the [10] by Tassiulas and Ephremides, where stochastic Lyapunov drift is used to develop a joint optimal routing and scheduling algorithm. The TassiulasEphremides in [11] are introducing single-hop radio network with random changing connectivity, with stability properties, and a policy that minimizes the queue delay, but they are not studding the recourse allocation problem under the assumption of milt-valued connectivities. However, the 
Lyapunov drift has since become a powerful technique for the development of stable scheduling strategies for wireless systems [11], [12], [13], [14], computer networks and switches [15], ad-hoc mobile networks [16], wireless sensor networks [17] and wireless mesh networks [18].

Other methods for joint stability and utility optimization via Lyapunov drift are developed for stochastic networks in [19] and [20] for application to flow control and energy minimization. An alternative approach is developed in [21] using stochastic gradient theory and fluid model transformations. In [22] the Lyapunov drift is also applied to wireless networks with multi-receiver diversity, where an optimal diversity backpressure routing algorithm is developed and shown to improve performance beyond that of related diversity algorithms that do not use backpressure.

Moreover, in [23] is presented an optimization problem to minimize the total energy consumed by the mobile users in executing a given service under total execution time constraints in the process of cloud offloading for multi-radio enabled mobile devices. The given optimization problem does not consider joint stability and performance optimization, since there is no usage of Lyapunov drift-plus-penalty technique and is not maximizing the average throughput. Despite all related works, this paper is applying a version of the Lyapunov drift-plus-penalty theorem in the future $5 \mathrm{G}$ mobile and fixed terminals, achieving high performance utility networks, stability and high level of QoS assurance, and is place on IP level, enriched with vertical multi-homing and multistreaming features.

\section{SYSTEM MODEL AND OPTIMIZATION}

The main characteristics of our $5 \mathrm{G}$ terminal with incorporated advanced QoS user-centric aggregation module with vertical multi-homing and multi-streaming features are illustrated in Figure 1 in [24]. The 5G terminal is multi-interface (multi-radio interface), with several $(M)$ interfaces, each for different RAT. Moreover, it can move with different velocities, if it is mobile $5 \mathrm{G}$ terminal or can be fixed if it is $5 \mathrm{G}$ proxy server, inside the $5 \mathrm{G}$ core network. The Advanced QoS-based User-centric Aggregation plus Lyapunov optimization (AQU Aplus) algorithm is set within the 5G terminal (in both terminals: fixed and mobile). To emphasize that this algorithm is explained in details in [24], and is extension of our AQUA algorithm placed within $5 \mathrm{G}$ mobile terminals and proxy servers, presented in related previous papers: [25] and [26].

Our proposed system model is consisted of three main parts: Sources of information, Processors and Queues. We are considering $N$ application sources, which are stationary independent processes with packet arrival rates $x_{1}, x_{2}, \ldots x_{\mathrm{i},}, \ldots, x_{\mathrm{N}}$ for every time slot $t$. Each source arrival process $x_{\mathrm{i}}(t)$ is entering in the dedicated processor $\mathrm{AL}_{\mathrm{i}}$ inside the Processors part. In this part, according to the AQUAplus optimization the AL processors are doing vertical multi-streaming and multi-homing processes ([27] and [28]) of division of one stream (traffic which is originating from one source), in order to go over different queues. The assigned weight factors $\left(w_{i j}\right)$ for each source arrival process $x_{\mathrm{i}}(t)$ are chosen within the interval $[0,1]$, with constraint: $\sum_{j=1}^{M} w_{i j}=1$, for $I=1,2, \ldots N$. Further, we are considering $M$ queue network with queue vector $\boldsymbol{Q}(\mathrm{t})=\left(Q_{1}(t), Q_{2}(t), \ldots, Q_{\mathrm{M}}(t)\right)$ that evolves in slotted time $t \in\{0,1,2,3, \ldots\}$ with update equation:

$$
Q_{m}(t+1)=\max \left[Q_{m}(t)+A_{m}(t)-\mu_{m}(t), 0\right],
$$

where $A_{m}(t)=\sum_{i=1}^{N} w_{i, m} x_{i}(t)$ is arrival rate variable for the $m$-th queue, and the parameter $\mu_{\mathrm{m}}(t)$ is output serving rate variable of the $m$-th queue, where $m \in\{1,2,3 \ldots M\}$. After each queue we are trying to achieve maximal output serving rate $\mu_{j}(t)$ on each interface $j=1,2, \ldots M$, so the sum of all output serving rates, over the time will be also with maximal value.

If we consider a random queue network state:

$$
\psi(t) \underset{=}{\Delta}\left[\left(\mu_{1}(t), \ldots, \mu_{M}(t)\right) ;\left(A_{1}(t), \ldots A_{M}(t)\right)\right],
$$

and a control policy action $\alpha_{\mathrm{L}}(t)$ which is made every slot $t$ with knowledge of the current state $\psi(t)$ and is chosen within some abstract action set $A_{\psi(t)}$. For simplicity we are assuming that the $\psi(t)$ process is i.i.d. over each slot. Also, we are considering a vector with time average power values for each interface as

Let the

$$
\overline{\mathbf{p}} \Delta\left(\overline{\underline{p_{1}(t)}}, \overline{p_{2}(t)}, \ldots, \overline{p_{M}(t)}\right) .
$$

$$
\overline{\mathbf{x}} \Delta\left(\overline{\underline{x_{1}}(t)}, \overline{x_{2}(t)}, \ldots, \overline{x_{N}(t)}\right)
$$

be a vector of the time average arrival rates $\left(x_{\mathrm{i}}(t)\right)$, and the $\theta(\overline{\mathbf{x}}) \underline{\underline{\Delta}} \sum_{m=1}^{M} \sum_{i=1}^{N} w_{i, m} \overline{x_{i}(t)}$ be the separable 
utility function of that vector, which is in the same time the objective function. Then, for each $5 \mathrm{G}$ terminal we are applying stochastic utility maximization framework to a simple flow (stream) based network model, so the following optimization problem in uplink (in the mobile 5G terminal) and downlink (in the fixed 5G terminal) is considered:

\section{Maximize: $\theta(\overline{\mathbf{x}})$}

Subject to:

1. Time average flow (stream) over the queue $Q_{m}(t)$ is less or equal to the time average maximal output serving rate on the interface $m$, i.e.:

$$
\sum_{i=1}^{N} w_{i, m} \overline{x_{i}(t)} \leq \mu_{m}^{\max } \quad \forall m \in\{1,2, \ldots, M\} .
$$

2. All queues $Q_{\mathrm{m}}(t)$ are rate stable, i.e.:

$$
\lim _{t \rightarrow \infty} \frac{\mathbf{E}\left\{\left|Q_{m}(t)\right|\right\}}{t}=0, \forall m \in\{1,2, \ldots, M\} .
$$

3. The desired time average power constraints are meet [20] $\left(p_{\mathrm{m}}(t)\right.$ is the power incurred in interface $m$ of the network on slot $t$, and $p_{\mathrm{m}}$ av is a required time average power expenditure), i.e.:

$$
\limsup _{t \rightarrow \infty} \overline{p_{m}(t)} \leq p_{m}^{a v} \quad, \forall m \in\{1,2, \ldots, M\} .
$$

4. For the control policy action: $\alpha_{L}(t) \in A_{\psi(t)}$.

For $t>0$, the used variables as time average over the first $t$ slots are defined for $m \in\{1,2,3, \ldots, M\}$, with:

$$
\begin{aligned}
& \overline{x_{m}(t)} \stackrel{\Delta}{=} \lim _{t \rightarrow \infty} \frac{1}{t} \sum_{\tau=0}^{t-1} \mathbf{E}\left\{x_{m}(t)\right\} ; \\
& \overline{p_{m}(t)} \stackrel{\Delta}{=} \lim _{t \rightarrow \infty} \frac{1}{t} \sum_{\tau=0}^{t-1} \mathbf{E}\left\{p_{m}(t)\right\} .
\end{aligned}
$$

For solving the above optimization problem we are using the Lyapunov drift-plus-penalty method (using fixed penalty control parameter V) given in [9]. We enforce the constraints 1, 2 and 3 of the optimization problem with the actual queue $Q_{\mathrm{m}}(t)$ (1) and the virtual queue for each $m$ :

$$
Z_{m}(t+1)=\max \left[Z_{m}(t)+\xi_{m}(t), 0\right],
$$

which is easy to shown that there are mean rate stable [9] (with finite queue length). In (6) the variables $\xi_{\mathrm{m}}(t)$ are auxiliary variables for $m \in\{1,2$, $3, \ldots, M\}$, defined as $\xi_{m}(t) \underline{\underline{\Delta}} p_{m}(t)-p_{m}^{a v}$. Moreover, if the low of telescoping sums is used over (6), then for any $t>0$ we have:

$$
Z_{m}(t)-Z_{m}(0) \geq \sum_{\tau=0}^{t-1} \xi_{m}(\tau)
$$

and therefore, dividing by $t$ and limes when $\mathrm{t} \rightarrow \infty$ yields:

$$
\lim _{t \rightarrow \infty} \frac{Z_{m}(t)}{t}-\lim _{t \rightarrow \infty} \frac{Z_{m}(0)}{t} \geq \lim _{t \rightarrow \infty} \frac{1}{t} \sum_{\tau=0}^{t-1} \xi_{m}(\tau),
$$

so it follows that if $Z_{\mathrm{m}}(t)$ is rate stable for all $m$, because limes $Z_{m}(t) / t \rightarrow 0$ with probability 1 , when $t \rightarrow \infty$, consequently the constraint (4) is satisfied with probability 1 .

Furthermore, we are defining a combining queue vector $\mathbf{S}(t) \underline{\underline{\Delta}}[\mathbf{Q}(t), \mathbf{Z}(t)]$ and the Lyapunov function as:

$$
L(\mathbf{S}(t)) \underline{\Delta} \frac{1}{2}\left[\sum_{i=1}^{M}\left(Q_{i}{ }^{2}(t)+Z_{i}^{2}(t)\right)\right] .
$$

If we define the one-step conditional Lyapunov drift with the:

$$
\Delta(\mathbf{S}(t)) \underline{\underline{\Delta}} \mathbf{E}\{L(\mathbf{S}(t+1))-L(\mathbf{S}(t)) \mid \mathbf{S}(t)\},
$$

then the Lyapunov drift-plus-penalty expression is defined as:

$$
\Delta(\mathbf{S}(t))+V \cdot \mathbf{E}\left\{\mathbf{u}\left(\alpha_{L}(t), t\right) \mid \mathbf{S}(t)\right\} .
$$

Above we define a "penalty" vector process as $\mathbf{u}\left(\alpha_{\mathrm{L}}(t), t\right)=\left(u_{0}{ }^{1}(t), \quad u_{0}{ }^{2}(t), \ldots, u_{0}{ }^{M}(t)\right)$, where $u_{0}^{m}(t)=-\sum_{i=1}^{N} w_{i, m} x_{i}(t)$ for $m \in\{1,2,3, \ldots, M\}$. The time average of those penalty processes we want to make less then (or equal to) some target value $u_{0}$. Those penalties are representing the incoming traffic arrival expenditures for the queuing, incurred by the control policy action $\alpha_{\mathrm{L}}(t)$ on slot $t$. Our AQUAplus algorithm seeks to minimize the upper bound of (10) for all $t$, all possible values of $\mathbf{S}(t)$, and all control parameters $V \geq 0$.

By squaring (1) and (6); then summarizing according to the (9) and (10), and then adding the "penalty" $V \cdot \mathbf{E}\left\{\mathbf{u}\left(\alpha_{\mathrm{L}}(t), t\right) \mid \mathbf{S}(t)\right\}$ to both sides, it is not difficult to show that the expression (10) has the following upper bound for all $t$ (for more details see [9]):

$$
\begin{aligned}
& \Delta(\mathbf{S}(t))+V \cdot \mathbf{E}\left\{\mathbf{u}\left(\alpha_{L}(t), t\right) \mid \mathbf{S}(t)\right\} \leq \\
& \quad \leq B-V \mathbf{E}\left\{\sum_{m=1}^{M} \sum_{i=1}^{N} w_{i, m} x_{i}(t) \mid \mathbf{S}(t)\right\}+ \\
& +\sum_{m=1}^{M} Q_{m}(t) \mathbf{E}\left\{\sum_{i=1}^{N} w_{i, m} x_{i}(t)-\mu_{m}(t) \mid \mathbf{S}(t)\right\}+ \\
& +\sum_{l=1}^{M} Z_{l}(t) \mathbf{E}\left\{\xi_{m}(t) \mid \mathbf{S}(t)\right\} .
\end{aligned}
$$


Here $B$ is a finite constant related to the worst-case second moments of $A_{\mathrm{m}}(t), \xi_{\mathrm{m}}(t)$, and $\mu_{\mathrm{m}}(t)$ processes, i.e.:

$$
\begin{aligned}
B \Delta & \frac{1}{2}\left(\sum_{m=1}^{M} \mathbf{E}\left\{\sum_{i=1}^{N}\left(\left(w_{i, m} x_{i}(t)\right)^{2}+\mu_{m}{ }^{2}(t)\right) \mathbf{S}(t)\right\}\right)+ \\
& +\frac{1}{2}\left(\sum_{l=1}^{M} \mathbf{E}\left\{\xi_{m}{ }^{2}(t) \mid \mathbf{S}(t)\right\}\right) .
\end{aligned}
$$

Furthermore, the goal of our AQUAplus algorithm is: to minimize the right-hand-side of the inequality (11), by choosing the most appropriate control policy action $\alpha_{L}(t) \in A_{\psi(t)}$ every slot $t$, observing the real and virtual queues vectors $\boldsymbol{Q}(t)$, $\boldsymbol{Z}(t)$ and the current state $\psi(t)$. In that way, the AQUA plus algorithm is solving the above discussed optimization problem, decoupling and reducing it into separate algorithms. The AQUA plus algorithm is given in more details in [24], where for solving the above optimization problem we are using the Lyapunov drift-plus-penalty method (using fixed penalty control parameter V) given in [9].

Furthermore, in Section 4, we are focusing on the upper bound of the consumed power and the lower bound for the battery life time for our proposed 5G terminals with AQUAplus algorithm within.

\section{CONSUMED POWER AND BATTERY LIFE TIME}

Let we have $Z_{\mathrm{m}}(t) \leq Z_{m}{ }^{\max }$, where the upper bound of the virtual queue $Z_{\mathrm{m}}(t)$ is defined as:

or each

$$
Z_{m}{ }^{\max } \triangleq Q_{m}{ }^{\max }+\left(p_{m}{ }^{\max }-p_{m}{ }^{a v}\right)
$$

$$
m \in\{1,2,3, \ldots, M\},
$$

where $Q_{m}{ }^{\text {max }}$ is maximal length of the real queue $Q_{m}(t)$, where we assumed that: $Q_{\mathrm{m}}(t) \leq Q_{m}{ }^{\max }$. From the other side, $p_{m}{ }^{\text {max }}$ is maximal power, that can be consumed on radio interface $m$, and $p_{m}{ }^{\text {av }}$ is a required average power expenditure on the radio interface $m$, as it was defined in the previous section.

Next we will prove that: for each positive number $T$, which is the number of time units for one time slot, the total consumed power for each radio network interface $m$, for each time slot $T$, is determined by the upper bound of the expression $T$ $p_{m}{ }^{\text {av }}+Z_{m}{ }^{\text {max }}$, i.e. the following inequality is satisfied:

$$
\begin{aligned}
& \sum_{\tau=t_{0}}^{t_{0}+T-1} p_{m}(\tau) \leq T \cdot p_{m}{ }^{a v}+Z_{m}{ }^{\max }, \\
& \forall t_{0} \in\{0,1,2 \ldots\}, \forall T \in\{1,2,3 . .\} .
\end{aligned}
$$

In order to prove the above upper bound, we will start from the equation (6), and also, we will assumed that $\xi_{m}(t) \underline{\underline{\Delta}} p_{m}(t)-p_{m}^{\text {av }}$. According to that, we have the following:

$$
Z_{m}(t+1)=\max \left[Z_{m}(t)+p_{m}(t)-p_{m}^{\mathrm{av}}, 0\right] .
$$

Applying the above defined upper bound for this virtual queue, i.e. assuming that $Z_{m}(t+1) \leq$ $Z_{m}{ }^{\max }$ we have the following inequality:

$$
\max \left[Z_{m}(t)+p_{m}(t)-{p_{m}}^{\text {av }}, 0\right] \leq Z_{m}{ }^{\max } .
$$

Let we start from the dynamic equation (15), and knowing that for each time slot $\tau \geq 0$ the following is satisfied:

$$
Z_{m}(\tau+1)-Z_{m}(\tau) \geq+p_{m}(\tau)-p_{m}^{\mathrm{av}} .
$$

If the above equation (17) is summarized on $\tau \in\left\{t_{1}, . . t_{2}-1\right\}$ and applying the low of telescoping sums (method of differences, i.e. differentials) we get:

$$
Z_{m}\left(t_{2}\right)-Z_{m}\left(t_{1}\right) \geq \sum_{\tau=t_{1}}^{t_{2}-1} p_{m}(\tau)-\sum_{\tau=t_{1}}^{t_{2}-1} p_{m}^{\mathrm{a} v}
$$

Next, replacing the $t_{1}=t_{0}$, and $t_{2}=t_{0}+T-1$, plus assuming that $p_{m}^{\text {av }}$ is a constant value, the expression (18) is transformed into:

$$
\begin{aligned}
Z_{m}\left(t_{0}+T-1\right)-Z_{m}\left(t_{0}\right) \geq \\
\quad \geq \sum_{\tau=t_{0}}^{t_{0}+T-1} p_{m}(\tau)-T \cdot p_{m}^{\mathrm{av}} .
\end{aligned}
$$

Because the expression from the left side of the inequality (18) for sure is equal or lower then $Z_{m}{ }^{\max }$ so, with small rearrangements, we proved that the (14) satisfied.

With that, the statement for the total consumed power for our proposed system model is proved, and is smaller or equal to $T \cdot p_{m}^{\mathrm{av}}+Z_{m}^{\max }$, i.e. is proportional to: the time for using all included radio interfaces, the average allowed power (for each interface) and the maximal backlog value of the network queues. If the values of the above mentioned parameters are lower, consequently the total consumed power should be smaller and the power supplies for the 5G terminal's battery will 
be also small. In that direction, the overall life time of the battery will be longer (the energy efficiency of the $5 \mathrm{G}$ terminal's battery will be with large value).

Furthermore, if we observe the radio network interface $m$, which is wireless transmitter and receiver, let his initially used energy is $E_{m}$ from the battery with total energy $E$ (where $E=\sum_{m=1}^{M} E_{m}$ ). Then, the guaranteed battery life time $\left(t_{\text {bat }}\right)$ for the proposed $5 \mathrm{G}$ terminal can be found by the derivation from the direct dependency of the total energy and the total battery power, i.e. from the following starting point:

$$
p_{\text {total }}(t)=\frac{E}{t_{b a t}},
$$

and from the fact that for a particular radio interface $m$, the total energy on the $m$-th interface is:

$$
E_{m}=t_{\text {bat }} \sum_{\tau=t_{0}}^{t_{0}+T-1} p_{m}(\tau), m \in\{1,2,3, \ldots M\} .
$$

By summarizing the (21) for all used radio network interfaces, the total energy $E$ could be found. Consequently, the battery life time (duration) for our proposed $5 \mathrm{G}$ terminal is:

$$
t_{b a t}=\frac{E}{\sum_{m=1}^{M} \sum_{\tau=t_{0}}^{t_{0}+T-1} p_{m}(\tau)}, m \in\{1,2,3, \ldots M\} .
$$

If on the last equation (22) we apply the equation (14) for the total consumed power of the network radio interface $m$, then the total battery life time is determined with the following expression:

$$
t_{\text {bat }} \geq \frac{E}{\sum_{m=1}^{M}\left(T \cdot p_{m}{ }^{\mathrm{av}}+Z_{k}{ }^{\max }\right)}=\frac{E}{M \cdot Z_{k}{ }^{\max }+T \sum_{m=1}^{M} p_{m}{ }^{\mathrm{av}}} .
$$

If we assumed that all radio network interfaces have the same average power expenditure, then we can get the particular equation for the battery life time of our proposed $5 \mathrm{G}$ terminal:

$$
t_{b a t} \geq \frac{E}{M \cdot\left(Z_{k}^{\max }+T p^{a v}\right)} .
$$

As can be noticed, the battery life time of the $5 \mathrm{G}$ terminal is determined by the existence of lower bound, given with the right side of the expressions (23) and (24). Consequently, the battery of the 5G terminal will have longer life, if the available energy per radio network interface is higher, and is inverse proportional from: the number of used interfaces $(M)$, maximal backlog value of the queues, the duration of the time slot $T$, and the value of the average power $\left(p^{\text {av }}\right)$ per radio interface. One can notice that the radio network interfaces which are not used (up) at the particular time slot should not be included in the calculations, so we can get longer battery life time for the $5 \mathrm{G}$ terminal. The derivation above (in the expression (24)) is solved by the assumption that all radio interfaces are launched (active) and that all of them are having the same average power expenditures $\left(p_{m}{ }^{\mathrm{av}}\right)$.

\section{SIMULATION RESULTS AND ANALYSIS}

In this section, we provide a simulation of the proposed AQUAplus algorithm for a 5G scenario including total wireless network coverage for the $2505 \mathrm{G}$ mobile terminals, from several RATs. The resulting average power for each interface within the $5 \mathrm{G}$ terminals is set to be $p_{m}{ }^{\text {av }}=0.7 \mathrm{~W}$. The control parameter is $V=10$. All exogenous stochastic inputs (sources) are independent Poisson processes, with three basic packet arrivals' rates: $\lambda_{1}=50$ packets $/ \mathrm{s}, \quad \lambda_{2}=24.316$ packets $/ \mathrm{s}$ and $\lambda_{3}=68.9655$ packets $/ \mathrm{s}$ (corresponding to the packet arrival's rates of VoIP, VoIP-conference and data, respectively). The Figure 1 shows simulation results over $10^{7}$ slots for the average sum queue backlog (in units of packets) versus different values for the total input packet arrival rate (different number of active application sources), when the complete arrival rate vector for $N=10$ sources is $\lambda$ $=[68.9655 ; 50 ; 24.316 ; 100 ; 50 ; 50 ; 24.316 ; 50$; $68.9655 ; 68.9655]$. If the number of sources is $N=$ 9 , then there will be summarized only first nine arrival rates from the vector $\lambda$ and etc. In all four cases the $5 \mathrm{G}$ mobile terminals are moving with average velocity of $40 \mathrm{~km} / \mathrm{h}$.

The maximal output serving rate vectors $\boldsymbol{\mu}_{\mathrm{M}}$ for all cases are:

$$
\begin{array}{r}
\text { - if } M=1, \text { then } \boldsymbol{\mu}_{1}=(1 / 250) \cdot[44643] ; \\
\text { - if } M=2 \text {, then } \boldsymbol{\mu}_{2}=(1 / 250) \cdot[44643 \cdot 12500] ; \\
\text { - if } M=4 \text {, then } \boldsymbol{\mu}_{4}=(1 / 250) \cdot[6694.4 \cdot 12500 \\
\cdot 5000-44643] ; \\
\text { - if } M=6 \text {, then } \boldsymbol{\mu}_{6}=(1 / 250) \cdot[6694.412500 \\
-500044643 \cdot 5000 \cdot 6694.4] .
\end{array}
$$




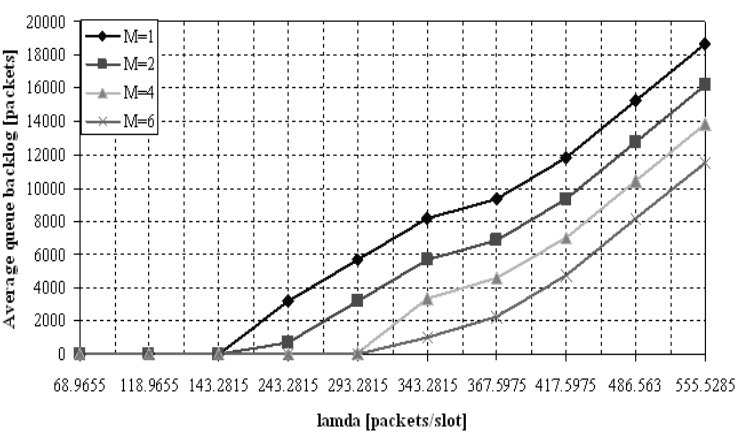

Fig. 1. Average queue backlog versus number interfaces in $5 \mathrm{G}$ terminals

Undoubtedly, as the total number of used interfaces in $5 \mathrm{G}$ terminals is higher, the average queue backlog is smaller. The case when they are 6 interfaces is achieving superior results for any number of data sources over other three cases (especially with the case when there is only one used interface and there is no Lyapunov drift-plus-penalty optimization technique, i.e. there is no AQUAplus algorithm within the used mobile terminals). To emphasize that the above maximal output rates are carefully chosen to be adequate to the maximal uplink serving rates (by dividing the uplink bit rates with the average number of bits per packet) of LTE/LTE-Advanced, IEEE 802.11n, IEEE 802.16e, IEEE 802.16m and IEEE 802.11ac RATs, shared between 250 mobile terminals in one cell.

By the Little's theorem [29] and [30], dividing the average queuing backlog with the average arrival rates yields an upper bound on average time delay. Consequently, in the case with more interfaces within 5G terminal with AQUAplus algorithm will cause minimal average time delay. It is noticeable that the delays start to rice when the number of sources is equal to the number of RAT interfaces which are launched $(M)$.

Furthermore, Figure 2 presents the average queue delays versus the average velocity of $5 \mathrm{G}$ mobile terminals, when the number of sources is fixed on $N=3$, with arrival rate vector $\lambda=\left[\lambda_{1} \lambda_{2} \lambda_{3}\right]$.

The maximal output serving rate vectors $\mu_{\mathrm{M}}$ for all cases are:

$$
\begin{aligned}
& \text { - if } M=1 \text {, then } \boldsymbol{\mu}_{1}=(1 / 250) \cdot \text { [6 694.4]; } \\
& \text { - if } M=2 \text {, then } \boldsymbol{\mu}_{2}=(1 / 250) \cdot \text { [6 694.4.12 500]; } \\
& \text { - if } M=3 \text {, then } \mu_{3}=(1 / 250) \cdot[6694.4 \cdot 12500 \\
& \text { 5000]; } \\
& \text { - if } M=4 \text {, then } \boldsymbol{\mu}_{4}=(1 / 250) \cdot[6694.4 \cdot 12500 \text {. } \\
& \cdot 5000.2250]
\end{aligned}
$$

$$
\begin{aligned}
& \text { - if } M=5 \text {, then } \boldsymbol{\mu}_{5}=(1 / 250) \cdot[6694.4 \cdot 12500 \\
& \cdot 5000 \cdot 2250 \cdot 12053.57] \text {. }
\end{aligned}
$$

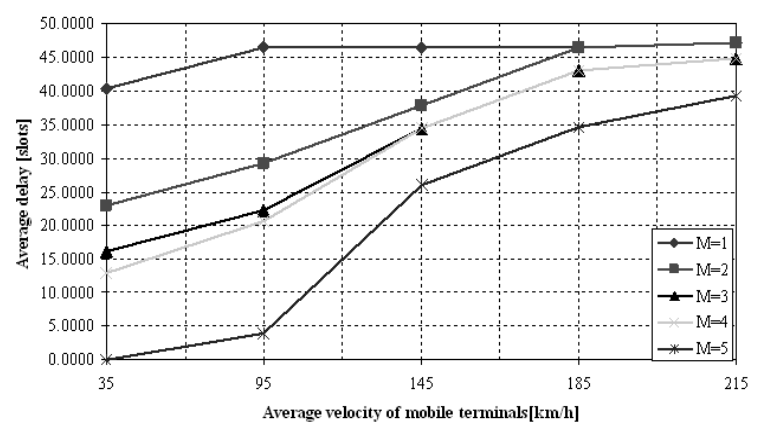

Fig. 2. Average delay versus average velocity of $5 \mathrm{G}$ mobile terminals.

It is evident that as the number of RAT interfaces is higher (i.e. for $M=5$ ) the value of the average delay is lower for each velocity, even it is with rising trend versus velocity. If there is only one RAT interface (there is no vertical multihoming and multi-streaming features) the average queue delay values are maximal (see the curve where $M=1$ in the Figure 2). Also, with smaller number of interfaces the average throughput is smaller and is supporting only those RAT interfaces belonging to the RAT with best mobility support. A key observation about the above algorithm is that it does optimal flow control decisions and simultaneously causing network queuing stability and minimal network queue delays. Moreover, as the number of available RATs is increasing more RAT interfaces are launched, so more superior overall performances are achieved. Also, we must take care of the trade-off between the battery life time (which is smaller when there are more active radio interfaces $(M)$ ) and the achievable throughputs included in the overall performance of the $5 \mathrm{G}$ terminals.

In the same time, we must to take in consideration the average power constrains for each radio interface, in order to avoid uncontrolled interference between the different RAT interfaces.

\section{CONCLUSION}

The paper presents a novel analytical frame work for $5 \mathrm{G}$ terminal with vertical multi-homing and multi-streaming features for $5 \mathrm{G}$ mobile broad band networks, which is maximizing the time average throughput and stabilize the queuing, simultaneously providing minimal queue backlog and 
minimal average queue delay. Also the upper bound of the consumed power and the lower bound of the battery life time for the proposed $5 \mathrm{G}$ terminals with AQUAplus algorithm within are presented. The 5G terminal with Lyapunov drift-pluspenalty technique implemented in the user 5G mobile terminals and in the $5 \mathrm{G}$ core network (e.g., in $5 \mathrm{G}$ proxy server or $5 \mathrm{G}$ cloud), is handling simultaneously multiple multimedia sources (applications) via multiple wireless and mobile network interfaces. The presented framework is leading to the practical policy control algorithms that are provably optimal and stable network, with high level of QoS provisioning.

Therefore the proposed $5 \mathrm{G}$ terminal can be easily generalized in a multi-RAT heterogeneous future $5 \mathrm{G}$ scenario, for different existing and future mobile broadband services globally, which are being typically accessed through mobile terminals, such as smartphones and lap-tops, due to higher penetration of mobile broadband compared to fixed broadband including developed and developing countries. In that manner, the next logical step is radio networks aggregation which will provide further increment in the data rates using the available RATs as well as future defined ones. Of course, for $5 \mathrm{G}$ there will be also new access schemes with higher spectrum utilization than $4 \mathrm{G}$. However, radio network aggregation feature, as proposed in this paper, provides possibility to combine even newly proposed 5G RATs with 4G RATs (LTE-Advanced and Mobile WiMAX 2.0), 3G RATs, as well as WLAN 802.11ac/ad/af. Finally, efficient QoS-based usage of available mobile resources is essential for implementation of the 5G paradigm and achieving the $5 \mathrm{G}$ desirable performances and goals.

\section{REFERENCES}

[1] Boccardi, F. et al.: Five Disruptive Technology Directions for 5G, IEEE Communications Magazine, Vol. 52, No. 2, pp. 74-80 (Nov. 2014).

[2] Bhushan, Naga et al.: Network Densification: The Dominant Theme for Wireless Evolution into 5G, IEEE Communications Magazine, Vol. 52, No. 2, pp. 82-89 (Nov. 2014).

[3] Bangerter, Boyd et al.: Networks and Devices for the 5G Era, IEEE Communications Magazine, Vol. 52, No. 2, pp. 90-96 (Nov. 2014).

[4] Cheng-Xiang Wang et al.: Cellular Architecture and Key Technologies for 5G Wireless Communication Networks, IEEE Communications Magazine, Vol. 52, No. 2, pp. 122-130 (Nov. 2014).
[5] Janevski, Toni: 5G Mobile Phone Concept, IEEE Consumer Communications and Networking Conference (CCNC) 2009, USA.

[6] Willie W. Lu: An Open Baseband Processing Architecture for Future Mobile Terminals Design, IEEE Wireless Communications, Vol. 15, Issue 2, pp. 110-119 (2008).

[7] Tudžarov, Aleksandar, Janevski, Toni: Design for 5G Mobile Network Architecture, International Journal of Communication Networks and Information Security, Vol. 3, No. 2, pp. 112-123 (2011).

[8] Soldani, D. et al. 5G Networks: End-To-End Architecture and Infrastructure, IEEE Communications Magazine, Vol. 52, No. 11, pp. 65-100 (Nov. 2014).

[9] Neely, M. J.: Stochastic Network Optimization with Application to Communication and Queueing Systems, Morgan \& Claypool, USA, 2010.

[10] Tassiulas, L., Ephremides, A.: Stability properties of constrained queueing systems and scheduling policies for maximum throughput in multihop radio networks, IEEE Transacations on Automatic Control, vol. 37, no. 12, (Dec. 1992).

[11] Tassiulas, L., Ephremides, A.: Dynamic server allocation to parallel queues with randomly varying connectivity, IEEE Trans. on Inform. Theory, vol. 39, pp. 466-478 (March 1993).

[12] Kahale, N., Wright, P. E.: Dynamic global packet routing in wireless networks. Proc. IEEE INFOCOM, 1997.

[13] Andrews, M., et al.: Providing quality of service over a shared wireless link, IEEE Communications Magazine, vol. 39, no. 2, pp. 150-154 (2001).

[14] Neely, M. J., Modiano, E., Rohrs, C. E.: Power allocation and routing in multi-beam satellites with time varying channels, IEEE Transactions on Networking, vol. 11, no. 1, pp. 138-152 (Feb. 2003).

[15] Kumar, P. R., Meyn, S. P.: Stability of queueing networks and scheduling policies, IEEE Trans. on Automatic Control, vol. 40,.no. 2, pp. 251-260 (Feb. 1995).

[16] Neely, M. J., Modiano, , E., Rohrs, C. E.: Dynamic power allocation and routing for time varying wireless networks. IEEE Journal on Selected Areas in Communications, vol. 23, no. 1, pp. 89-103 (Jan. 2005).

[17] Sridharan, A., Moeller, S., Krishnamachari, B.: Making distributed rate control using Lyapunov drifts a reality in wireless sensor networks, In: Modeling and Optimization in Mobile, Ad Hoc, and Wireless Networks and Workshops, 2008. WiOPT 2008. 6th International Symposium on, 1-3 April 2008, pp.452-461,

[18] Neely, Michael J., Urgaonkar, Rahul: Cross-layer adaptive control for wireless mesh networks. Ad Hoc Networks (Elsevier Journal), Vol. 5, No. 6, pp. 719-743 (August 2007).

[19] Georgiadis, L., Neely, M. J., Tassiulas, L.: Resource allocation and cross-layer control in wireless networks, Foundations and Trends in Networking, vol. 1, no. 1, pp. 1-149 (2006).

[20] Neely, M. J.: Energy optimal control for time varying wireless networks, IEEE Transactions on Information Theory, vol. 52, no. 7, pp. 2915-2934 (July 2006).

[21] Lee, J. W., Mazumdar, R. R., Shroff, N. B.: Opportunistic power scheduling for dynamic multiserver wireless systems, IEEE Transactions on Wireless Communications, vol. 5, no. 6, pp. 1506-1515 (June 2006). 
[22] Neely, M. J.: Optimal backpressure routing for wireless networks with multi-receiver diversity, Proc. of Conf. on Information Sciences and Systems (CISS), March 2006.

[23] Mahmoodi, S. E., Subbalakshmi, K. P., Sagar, V.: Cloud offloading for multi-radio enabled mobile devices, 2015 IEEE International Conference on Communications (ICC), London, 2015, pp. 5473-5478.

[24] Shuminoski, T., Janevski, T.: Lyapunov Optimization Framework for 5G Mobile Nodes with Multi-Homing, In: IEEE Communications Letters, Vol. 20, No. 5, pp. 10261029 (May 2016).

[25] Shuminoski, Tomislav, Janevski, Toni: 5G mobile terminals with advanced QoS-based user-centric aggregation (AQUA) for heterogeneous wireless and mobile networks. Wireless Networks (Springer journal). [Online]. 21 (6), pp. 1-18 (2015, Aug.).
[26] Shuminoski, Tomislav, Janevski, Toni.:. Radio Network Aggregation for $5 \mathrm{G}$ Mobile Terminals in Heterogeneous Wireless and Mobile Networks. Wireless Personal Communication, Springer journal. [Online]. 78 (2), pp. 1211-1229 (May, 2014).

[27] Rec. ITU-T Y.2052: Framework of multi-homing in IPv6based NGN (02/2008).

[28] Rec. ITU-T Y.2056: Framework of vertical multihoming in IPv6-based Next Generation Networks, (08/2011).

[29] Bertsekas, D. P., Gallager, R.: Data Networks, New Jersey: Prentice-Hall, Inc., 1992.

[30] ITU-T Study Group 2 (Working Party 3/2) and ITU-D SG 2/16 \& ITC (Draft 2001-06-20), Teletraffic Engineering, Handbook, editor: Villy B. Iversen., Geneva, December 2003. Link:<https://www.itu.int/dms_pub/itu-d/ opb/stg/D-STG-SG02.16.1-2001-PDF-E.pdf 
